\title{
Eosinophilic Granuloma of the Occipital Bone Presenting as Intracranial Venous Hypertension
}

\author{
H. Wightman and B. Wheelock
}

\begin{abstract}
Intracranial venous sinus thrombosis is an uncommon cause of pseudotumor cerebri. The diagnosis is often not confirmed on the rationale that treatment will not be altered. We report a case presenting a pseudotumor cerebri where the underlying pathology disclosed dural sinus thrombosis resulting from compression by an eosionophilic granuloma of the occipital bone. Routine CT of the head and Technetium- $99 \mathrm{~m}$ brain scan initially demonstrated neither tumor nor thrombosis. Plain skull $x$-rays subsequently revealed a lytic lesion of the occiput. When reinvestigated with CT using bone density windows the tumor was revealed. Excision of the tumor and a short course of cobalt therapy was curative. Special techniques in nuclear scanning, CT and MRI designed to improve the sensitivity for diagnosing venous sinus thrombosis are described. This case illustrates the importance of establishing a definitive diagnosis and shows the importance of pre-test consultation between clinicians and radiologists to ensure that specific investigative techniques are properly utilized.
\end{abstract}

\begin{abstract}
RÉSUMÉ: Granulome éosinophile de l'os occipital se manifestant par une hypertension veineuse intracrânienne La thrombose de sinus veineux intracrâniens est une cause peu fréquente du syndrome d'hypertension intracrânienne bénigne. Le diagnostic souvent n'est pas confirmé, cette attitude étant justifiée par le fait que le traitement n'en sera pas modifié. Nous rapportons un cas qui s'est présenté comme un syndrome d'hypertension intracrânienne bénigne alors que la pathologie sous-jacente était une thrombose du sinus dural résultant d'une compression par un granulome éosinophile de l'os occipital. Un CT scan de routine de la tête et un scan du cerveau au technétium- $99 \mathrm{~m}$ n'avaient initialement démontré ni tumeur, ni thrombose. Des radiographies simples du crâne ont montré par la suite une lésion lytique de l'occiput. Lors d'une réinvestigation par CT scan utilisant des fenêtres pour la densité osseuse, la tumeur a été mise en évidence. L'excision de la tumeur et une cobalt thérapie brève ont entraîne la guérison. Nous décrivons des techniques spéciales de scanning nucléaire, le CT et la RMN, destinées à améliorer la sensibilité dans le diagnostic de la thrombose de sinus veineux. Ce cas illustre l'importance d'établir un diagnostic définitif et montre l'importance de la consultation pré-test entre les cliniciens et les radiologiques pour s'assurer que les techniques spécifiques d'investigation sont utilisées adéquatement.
\end{abstract}

Can. J. Neurol.Sci. 1991; 18:512-514

Intracranial venous sinus thrombosis is a well recognized but uncommon condition in children and adults. Historically it has been associated with infective intracranial processes such as mastoiditis and periorbital cellulitis. As a result of widespread use of antibiotics it is now more frequently aseptic in origin associated with states predisposing to thrombosis ${ }^{1-6}$. Venous sinus thrombosis has been suspected (but less frequently confirmed) as a cause for pseudotumor cerebri. In spite of major advances in diagnostic imaging with increased efficacy and safety, not all clinicians have pursued this specific diagnosis, accepting instead the less definitive diagnosis pseudotumor cerebri. This is especially true when no change in treatment is anticipated. We describe a case initially diagnosed as pseudotumor cerebri where pursual of a definitive diagnosis resulted in significant modification in treatment and outcome for the patient.

\section{Case Report}

A ten-year-old Caucasian male was well until one month prior to admission when he developed symptoms of an upper respiratory infection. He was treated with two courses of antibiotics before his symptoms completely resolved. Approximately one week later he developed a severe headache which became persistent, associated with recurrent vomiting, photophobia and decreased energy. His headache was worse in the mornings and he would awaken at night with the pain. After six days he saw a pediatrician. Past history included a congenital partial ptosis of his right eye and tonsillectomy at age five. On exam he was afebrile with normal vital signs. His general medical examination was unremarkable except for the fundoscopy which revealed bilateral disc edema.

From the Department of Neurosurgery, Saint John Regional Hospital, Saint John

Received June 13, 1990. Accepted in final form March 26, 1991.

Reprint requests to: Dr. W. Brian Wheelock, Department of Neurosurgery, Saint John Regional Hospital, Saint John, New Brunswick, Canada 
He was admitted to hospital where cranial CT with enhancement was done and reported as normal; it was noted that he had small ventricles. Lumbar puncture was performed which revealed an elevated opening pressure of $51 \mathrm{~cm}$ water. His cerebrospinal fluid (CSF), cell count, and chemistry were normal. Following the LP he had significant improvement in his headache and vomiting.

One week later he had recurrence of severe headache and vomiting associated with worsening of his papilloedema. Repeat LP revealed an opening pressure of $52 \mathrm{~cm}$ water. CSF was removed until the pressure was reduced to $25 \mathrm{~cm}$ water. Analysis of the fluid was again normal. His symptoms improved transiently but then recurred and he was transferred to our centre.

On arrival he was agitated and crying. His vital signs were normal. There was mild meningismus. Papilloedema was present bilaterally. He had a partial right abducens nerve palsy. There was one centimeter, mildly tender, mid-occipital nodule interpreted as lymphadenopathy. Cranial CT was unchanged from previous studies. Mastoid x-rays were normal. Technetium brain scan with static and dynamic imaging suggested normal distribution in the dural sinuses.

A plain occipital skull $x$-ray was done assessing the tender occipital lump initially suspected as lymphadenopathy. This revealed a large lytic lesion of the occiput at the torcula, extending slightly to the right of the midline (Figure 1). Review of the initial CT scan done with brain density windows only, had failed to demonstrate this abnormality. A repeat CT scan of the occipital region with bone density windows revealed a diploe/inner table tumor extending through the outer table corresponding with the tenderness of his right occiput and the lesion seen on plain skull x-ray (Figure 2a, b).

A craniotomy was performed and at surgery an occipital bone tumor was found infiltrating and compressing the superior sagittal sinus and dura adjacent to it on the right. The superior sagittal sinus was distended and the right lateral sinus had no demonstrable filling, presumably a result of the compressive effects of the tumor. Pathology of the tumor revealed an eosinophilic granuloma. Post-operative cobalt therapy con-

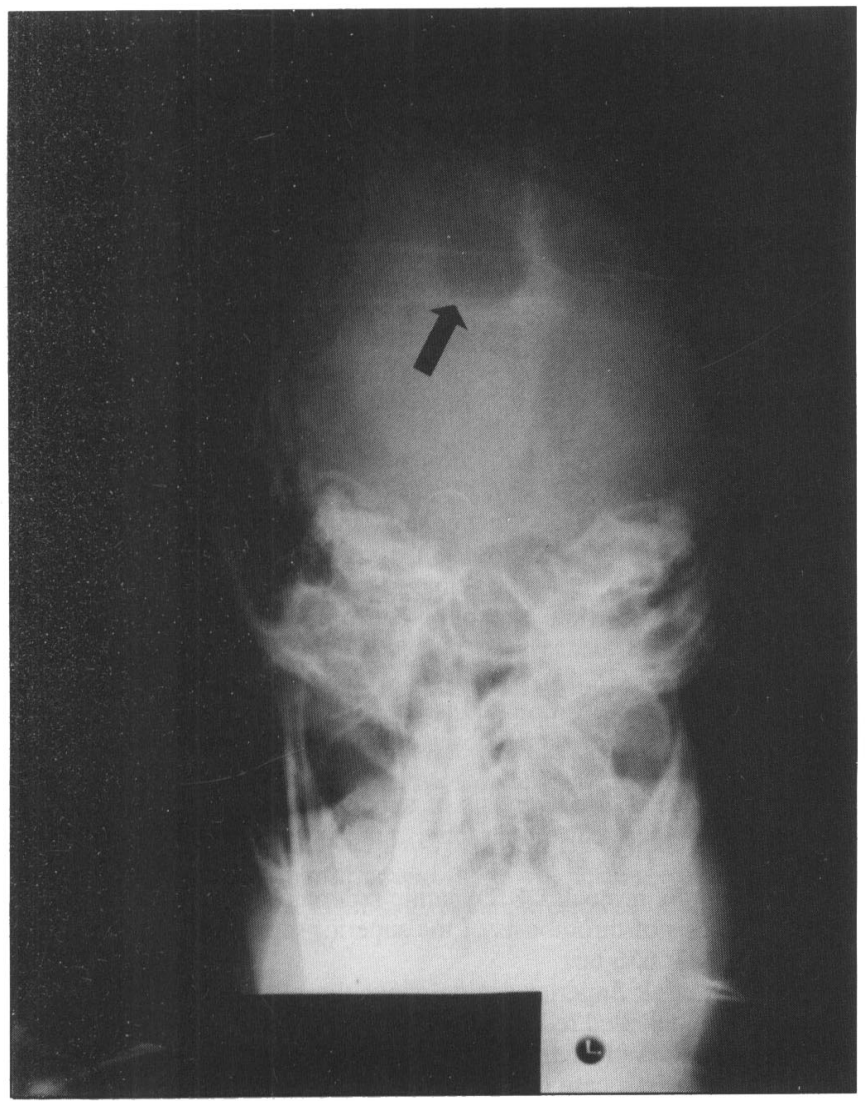

Figure 1. Occipital skull x-ray demonstrating lytic lesion (see arrow). sisting of $300 \mathrm{cGy}$ in three doses was delivered to the affected area. Following radiotherapy a cranioplasty was performed. At this second surgery there was still some distension of the superior sagittal sinus but filling of the right lateral sinus was demonstrable. Bone scan of his whole body revealed no other evidence of increased uptake suggesting his eosinophilic granuloma was solitary. He has done well in follow up.

\section{Discussion}

Pseudotumor cerebri, first described by Quinke in 1893, is now considered a disorder of intracranial pressure regulation in which CSF pressure is elevated without clinical, laboratory or radiologic evidence of focal lesions, meningeal inflammation or hydrocephalus. ${ }^{6}$ It is an uncommon diagnosis in children and adults and recent reviews have summarized various conditions associated with the syndrome. ${ }^{6-9}$ The diagnosis is based on four criteria $^{6}$ (Table 1 ).

Dural sinus thrombosis can present as pseudotumor cerebri and has frequently been cited as an association or cause.

$\mathbf{A}$

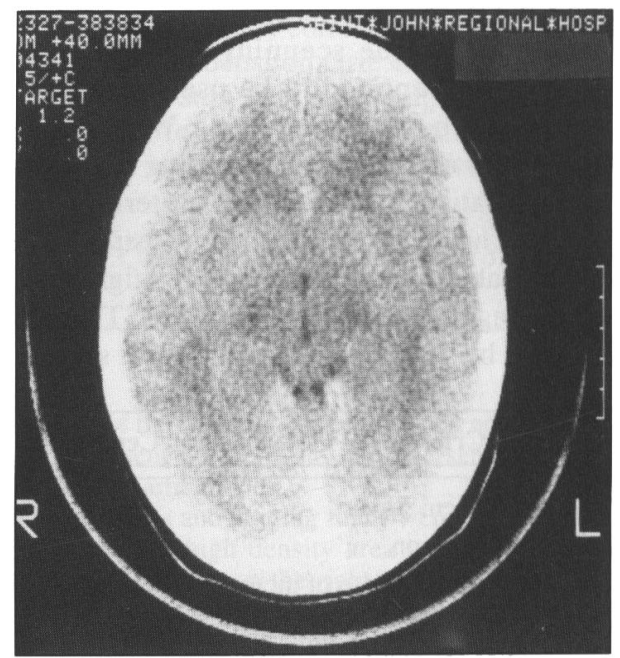

B

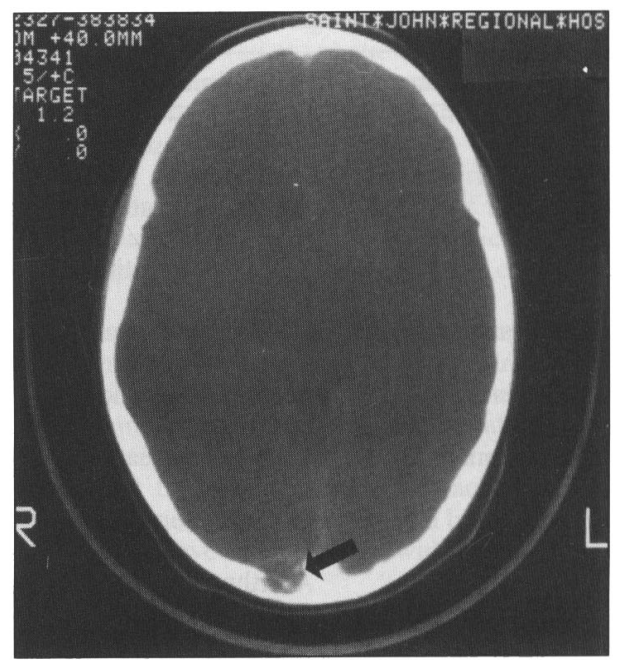

Figure 2. (A) Contrast enhanced CT scan using brain density window reported as normal. (B) Same level using bone density window. Note lytic lesion of occipital bone (see arrow) confirmed at surgery to be an eosinophilic granuloma. 
Ahlskog and O'Neill's recommendation 6 that these patients be considered a separate entity bears clinical importance as treatment may be modified by demonstration of sinus thrombosis. 10,11

Intracranial venous sinus thrombosis has been associated with a variety of conditions (Table 2 ). Early reviews noted up to $39 \%$ of cases in children resulting as a complication of middle ear infection. ${ }^{8}$ In Couch et al.'s more recent series, only $8 \%$ resulted from otitis media or its complications. ${ }^{7}$

We believe this is the first reported case of eosinophilic granuloma causing dural sinus thrombosis and presenting as pseudotumor cerebri. Routine CT imaging failed to demonstrate the bony defect later clearly demonstrated with $\mathrm{CT}$, utilizing bone density windows. The large lytic lesion seen on plain skull $\mathrm{x}$-ray prompted the repeat CT. Several authors have published cases where contrast enhanced CT scanning has demonstrated both the presence and resolution of thrombus in the posterior superior sagittal sinus (Empty Triangle Sign or Delta Sign). 13,14,15. Zilkha and Diaz offer advice on how to increase the sensitivity of this method and its major pitfalls. ${ }^{12}$

Dynamic radionucleide scanning with technetium-99m DTPA has also been reported to be useful in demonstrating venous sinus thrombosis. Barnes and Winestock describe increased sensitivity of this procedure using an 80-lens optical camera with the patient's head in the posterior oblique position. ${ }^{14}$ Front et al. have reported their five year experience with technetium-99m labelled red blood cell scintigraphy for suspicion of superior sagittal sinus thrombosis (SSST). 15 Static imaging was found to be $100 \%$ sensitive and $86 \%$ specific for SST

\section{Table 1: Diagnostic Criteria for Pseudotumor Cerebri}

1. ICP greater than $20 \mathrm{~cm}$ water

2. Normal CSF composition.

3. Signs and symptoms are those of increased ICP alone with no alteration of consciousness.

4. Radiologic studies are normal.

Table 2: Causes of Intracranial Venous Sinus Thrombosis

\begin{tabular}{ll}
\hline Septic Causes & Aseptic Causes \\
Otitis Media & Pregnancy, Puerertium \\
Mastoiditis & Oral contraceptives \\
Paranasal sinusitis & Dehydration, cachexia \\
Periorbital cellulitis & Ketoacidosis, shock \\
Penetrating trauma & Congestive heart failure \\
& Inflammatory bowel disease \\
& Antithrombin III deficiency \\
& Sickle cell disease \\
& Thrombocytosis \\
& Trauma \\
& Antiphospholipid antibodies \\
\hline
\end{tabular}

when compared to angiography. In our patient, the diagnostic sensitivity of both CT and nuclear scans could have been increased had these techniques specific to investigation of venous sinus thrombosis been employed.

Recently there have been reports describing the superiority of MRI in demonstrating both superficial and deep cerebral venous thrombosis 16,17 and it is now the preferred method for demonstrating cerebral venous thrombosis. Where MRI is not available, cerebral angiography may be helpful in demonstrating dilated corkscrew veins, shunting of blood and filling defects in the involved sinus.

This case confirms the importance of ruling out venous sinus thrombosis as a cause of pseudotumor cerebri. The diagnosis in our patient led to successful management of the tumor and underlying intracranial hypertension. Plain skull films, frequently ignored in favor of more advanced technology, were helpful on this occasion. Specialized CT and radionucleide techniques, and now MRI imaging are the procedures of choice in diagnosing venous sinus thrombosis. Consultation with the radiologist may enhance their diagnostic sensitivity.

\section{ACKNOWLEDGEMENTS}

Special thanks to Christa MacPhee and Dr. C. Maxner for their help in preparation of the manuscript.

\section{REFERENCES}

1. Cecil Textbook of Medicine. 18th ed. Wyngaarden JB, Smith LH. WB Saunders Co. 1988.

2. Gettelfinger DM, Kokeman EP. Superior sagittal sinus thrombosis. Arch Neurol 1977; 34: 2-6.

3. Imai WK, Everhart FR, Sanders JM. Cerebral venous sinus thrombosis: report of a case and review of the literature. Pediatrics 1982; 70: 965-970.

4. Lavin PJM, Bone I, Lamb JT, et al. Intracranial venous thrombosis in the first trimester of pregnancy. J Neurol Neurosurg Psychiatry 1978; $41: 726-729$.

5. Averbach P. Primary cerebral venous thrombosis in young adults: diverse manifestations of an unrecognized disease. Ann Neurol 1978; 3: 81.

6. Ahlskog JE, O'Neill BP. Pseudotumor cerebri. Ann Intern Med 1982; 97: 249-256.

7. Couch R, Camfield PR, Tibbles JAR. The changing picture of pseudotumor cerebri in children. Can J Neurol Sci 1985; 12: 48-50.

8. Rose A, Matson DD. Benign intracranial hypertension in children. Pediatrics 1967; 39: 227-237.

9. Corbett JJ. Problems in the diagnosis and treatment of pseudotumor cerebri. Can J Neurol Sci 1983; 10: 221-229.

10. Greer M. Benign intracranial hypertension, I. Mastoiditis and lateral sinus obstruction. Neurology 1962; 12: 472-474.

11. Scully RE, et al. Case preparation 20-1988. N Engl J Med 1988; 318: 1322-1328

12. Zilkha A, Diaz A. Computed tomography in the diagnosis of superior sagittal sinus thrombosis. J Comput Assist Tomogr 1980; 4: 124-126.

13. D'Avella D, et al. Diagnosis of superior sagittal sinus thrombosis by computerized tomography: report of two cases. J Neurosurg 1984; 61: 1129-1131.

14. Barnes B, Winestock DP. Dynamic radionucleotide scanning in the diagnosis of thrombosis of the superior sagittal sinus. Neurology 1977; 27: 656-661.

15. Front $D$, et al. Superior sagittal sinus thrombosis: assessment with Tc-99m labelled red blood cells. Radiology 1986; 158: 453-456.

16. Baver WM, Einhaupl K, Heywang SH, et al. MR of venous sinus thrombosis: a case report. Am J Neuroradiol 1987; 8: 713-715.

17. Ashforth RA, Melanson D, Ethier R. MR of deep cerebral venous thrombosis. Can J Neurol Sci 1989; 16: 417-421. 